\title{
Phenological tracking of a seasonal climate window in a recovering tropical island bird species
}

\author{
Joseph Taylor ${ }^{1,2,3}$ (D) Malcolm A. C. Nicoll ${ }^{2}$ (D) Emily Black ${ }^{4,5}$. \\ Caroline M. Wainwright ${ }^{4,5}$ (D) $\cdot$ Carl G. Jones ${ }^{6,7} \cdot$ Vikash Tatayah $^{7}$ (D) \\ Pier Luigi Vidale ${ }^{4,5} \cdot$ Ken Norris ${ }^{2,8}$
}

Received: 30 April 2020 / Accepted: 6 January 2021/Published online: 12February 2021

(C) The Author(s) 2021

\begin{abstract}
Constraints on evolutionary adaptation and range shifts mean that phenotypic plasticity, which includes physiological, developmental or behavioural responses to environmental conditions, could be an important mode of adaptation to a changing climate for many species with small insular populations. While there is evidence to suggest adaptive plasticity to climate in some island populations, little is known about this capacity in species that have experienced a severe population bottleneck. In a changing climate, plasticity in the timing of life-history events, such as in breeding phenology, is adaptive if timing is optimised in seasonal environments, although these processes are poorly understood for tropical species. Here, we quantify the effects of climate on the breeding phenology and success of the Mauritius kestrel (Falco punctatus), a tropical raptor whose extinction has been averted by conservation management. We show that the timing of egg-laying is advancing in response to warming, at rates similar to temperate bird populations. Individual females show plasticity to temperature, although there is limited variation among individual responses. We show that advances in breeding phenology are likely to be adaptive, as they track changes in a seasonal climate window of favourable conditions, defined by late winter-early spring temperatures and the onset of the summer rainy season. Our results provide a rare example of a small and bottlenecked insular population that has adjusted to recent climate change through phenotypic plasticity. Furthermore, seasonal climate windows and their dynamics may be widespread mechanisms through which tropical species are impacted by and respond to climate change.
\end{abstract}

Keywords Mauritius kestrel · Falco punctatus $\cdot$ Threatened species $\cdot$ Conservation

Joseph Taylor

joseph_taylor22@outlook.com

$\triangle$ Emily Black

e.c.l.black@ reading.ac.uk

Extended author information available on the last page of the article 


\section{Introduction}

The vulnerability of species to climate change can be assessed through a framework of exposure, sensitivity and adaptive capacity (Williams et al. 2008; Dawson et al. 2011). Adaptive responses to a changing climate may involve physiological and behavioural (phenotypic) plasticity, spatial or elevational range shifts or evolutionary changes, without which local extirpation or complete extinction are increasingly likely (Williams et al. 2008; Dawson et al. 2011) and management interventions become necessary (e.g. Pearce-Higgins et al. 2019). Island-endemic species are generally regarded as particularly vulnerable to climate change. Their limited distributions increase population-level exposure to climate risks and limit the scope for dispersal and spatial shifts (Foden et al. 2013). The impacts of human activities are particularly acute on islands (Kier et al. 2009), and the isolated evolution of island biotas increases their vulnerability to novel threats, such as non-native species (Berglund et al. 2009). Human-caused impacts may also reduce the resilience of populations to climate change (Parmesan et al. 2000). Small population size can limit genetic diversity and the potential for evolutionary adaptation to new pressures (Parmesan et al. 2000), and adaptive capacity may be particularly compromised in species that have experienced a population bottleneck (Nicotra et al. 2015).

Given the constraints that may be imposed by low genetic diversity and limited dispersal options, phenotypic plasticity could represent the only likely mode of adaptation to climate change for many island-endemic species. Phenotypic plasticity is the direct influence of the environment on the expression of traits in individuals across spatial or temporal variations in conditions, and it represents an important mode of adaptation to rapid environmental change (Donelson et al. 2018). Individual plasticity occurs via reaction norms, which are expected to be under natural selection if they have a heritable component (Nussey et al. 2007). If environmental conditions exceed the potential for reaction norms to maintain fitness, genetic and epigenetic diversity in plasticity is required for adaptation (Beever et al. 2016), without which extinction becomes more likely (Oostra et al. 2018).

Among vertebrates, there is evidence to suggest adaptive plasticity in island populations of reptiles and amphibians (e.g. Wikelski and Thom 2000; Lind and Johansson 2007), and bird species with widespread ranges (Porlier et al. 2012). Little is known, however, about the potential for adaptive plasticity to climate change in extremely rare and genetically bottlenecked species. Plasticity to climate change may be constrained in small island populations of birds, such that responses fail to be adaptive, perhaps because of low genetic diversity (Gordo and Doi 2012). Some island species that have recovered from population bottlenecks, such as the Seychelles warbler (Acrocephalus sechellensis), have demonstrated adaptability in their overall breeding seasonality in response to environmental conditions (Komdeur 1996; Komdeur and Daan 2005). However, further research is required to investigate the potential for phenotypic plasticity to stabilise demographic rates and avert or delay the extinction of small island populations due to climate change.

Changes in phenology (the timing of seasonal life-history events) are among the most frequently cited examples of ecological response to climate change (Forrest and MillerRushing 2010; Post et al. 2018), and are driven in part by phenotypic plasticity (e.g. Visser 2008). The timing of reproduction is an important life-history decision, as it mediates the relationship between environmental conditions and reproductive fitness (e.g. Visser and Both 2005). The advancement of spring phenology, such as flowering times in plants and the timing of breeding in animals, has been documented for a range of taxonomic groups and life-history 
traits, most frequently in temperate regions of the Northern Hemisphere (Cohen et al. 2018; Post et al. 2018). Evidence indicates that phenological advancement is generally more rapid at higher latitudes, owing largely to the increasing velocity of warming with increasing latitude (Both et al. 2004; Post et al. 2018). In a changing climate, species that rely on climate cues for their phenology risk mistiming their activities relative to peaks in important resources (e.g. trophic mismatch; Visser and Both 2005) or to a window of favourable abiotic conditions (Miller-Rushing et al. 2010).

Bird populations in temperate regions have provided model systems for the study of climate change impacts on phenology and trophic mismatch, but very little is known about the implications of climate change for the phenology of bird species in the tropics (Charmantier and Gienapp 2014; Hidalgo Aranzamendi et al. 2019). While temperature is the dominant climate influence on phenology in temperate regions, variation in precipitation is thought to become increasingly important at lower latitudes (Forrest and Miller-Rushing 2010; Pearce-Higgins and Green 2014; Cohen et al. 2018). However, the influence of temperature on tropical species is often not tested and compared to that of precipitation. Many tropical bird species breed seasonally and have phenological patterns that are influenced by climate (e.g. Wikelski et al. 2003). Temporal variation in biotic and abiotic conditions in tropical regions may therefore be sufficient for climate change to impact phenology and have consequences for individual fitness and population dynamics (Komdeur 1996; Senapathi et al. 2011; Hidalgo Aranzamendi et al. 2019), but these processes are poorly understood. While the velocity of warming has been most rapid at higher latitudes, tropical regions, with their more limited temperature variation, are projected to be among the first to emerge from recent variability into relatively novel climate regimes (Williams et al. 2007; Mora et al. 2013; Hawkins et al. 2014; Mahony and Cannon 2018). However, there is a shortage of long-term detailed datasets and studies on the demographic impacts of climate change in tropical species.

Here, we address these issues using a detailed, individual-based dataset on a reintroduced population of a tropical wild bird, the Mauritius kestrel (Falco punctatus). This species was once one of the rarest birds in the world, but a successful recovery programme has averted its extinction. Mauritius is one of the few countries to have made net gains in vertebrate biodiversity in recent decades (Rodrigues et al. 2014), and this species' recovery contributes to such achievements. Mauritius has a tropical climate with a summer rainy season, as influenced by tropical cyclones and orographic rain brought by the Southeast Trade Winds (Senapathi et al. 2010; Staub et al. 2014). The focal population occupies the Bambou Mountains in eastern Mauritius, which form a trade wind belt and receive high rainfall relative to most parts of the island (Staub et al. 2014). The birds start to breed in the dry austral spring, with many young fledging early in the warmer summer rainy season. Mauritius kestrels exhibit limited dispersal and the focal population is effectively isolated (Nevoux et al. 2013; Cartwright et al. 2014), allowing the monitoring of virtually all individuals and breeding attempts. These data enable the combination of individual life-history data on the timing of breeding and its fitness consequences with climate records spanning $>20$ years. This provides a rare opportunity to investigate the potential for phenological plasticity in a small and bottlenecked population in response to a changing climate. We address three broad questions: (1) how is breeding phenology (timing of egg-laying) responding to a changing climate and is there evidence for plasticity; (2) how does climate impact breeding success; and (3) is there evidence that breeding phenology is adaptive in relation to climate impacts on breeding success? 


\section{Materials and methods}

\subsection{Study species}

The Mauritius kestrel is a diurnal, accipiter-like falcon, endemic to Mauritius. It is a monogamous and territorial cavity-nester, and tends to favour native forest (Jones 1987), although it also occupies agricultural areas. Its principal prey are endemic arboreal day geckos (Phelsuma spp.) (Temple 1987), but it will also hunt other native and introduced vertebrates and some insects (Jones 1987; Temple 1987). The species has been the subject of a successful recovery programme since it suffered a severe population bottleneck and neared extinction in the wild in the 1970s (Jones et al. 1995). Threats to the Mauritius kestrel have included habitat destruction, introduced invasive species and pesticide pollution. Management strategies used in the recovery programme include captive-breeding and releases, cross-fostering, provision of nestboxes, supplementary feeding and control of invasive species (Jones et al. 1995). The species became locally extinct in the Bambou Mountains in the 1950s, but was reintroduced from 1987 onwards (Jones et al. 1995), and the population has since stabilised at $\sim 50$ breeding pairs. The current Bambou Mountains population is significantly inbred and has lost substantial genetic diversity, although the consequences for the species are unclear (Groombridge et al. 2000; Ewing et al. 2008). Breeding Mauritius kestrels lay clutches of 1-5 eggs (Jones et al. 1995). Egg-laying starts in September and the last chicks fledge in January or February (Cartwright et al. 2014). The vast majority of the population is colour-ringed and monitored during each breeding season, with nest-sites checked regularly. This study utilises data on individual nesting attempts. Nest visits by field workers are often irregular, which means that egg-laying dates usually have to be estimated (see Supplementary Methods).

\subsection{Meteorological data}

Daily rain gauge data from Mt Camizard ( $20^{\circ} 20^{\prime} \mathrm{S}, 57^{\circ} 42^{\prime} \mathrm{E}, 21 \mathrm{~m}$ asl) for the period January 1962-March 2016 were collected by Ferney Sugar Estate. The Mt Camizard rain gauge is situated in a central location in the Bambou Mountains range of the Mauritius kestrel and has been shown to be representative of seasonal rainfall trends in other parts the Bambou Mountains area (Senapathi et al. 2010). Daily temperature data from the nearest available synoptic station at Plaisance $\left(20^{\circ} 26^{\prime} \mathrm{S}, 57^{\circ} 41^{\prime} \mathrm{E}, 50 \mathrm{~m}\right.$ asl; c. $11 \mathrm{~km}$ from Mt Camizard) for the period January 1951-January 2016 were obtained via the US National Oceanic and Atmospheric Administration (NOAA) in the form of the GHCN (Global Historical Climatology Network) and GSOD (Global Summary of the Day) inventories. These inventories were merged to minimise the number of days with missing data. Tropical cyclone tracks and accompanying data were downloaded as ESRI shapefiles from the International Best Track Archive for Climate Stewardship (IBTrACS v03r10) (Knapp et al. 2010) via NOAA (www. ncdc.noaa.gov/ibtracs). Further details are provided in the Supplementary Methods.

\subsection{Exploratory analyses of climate effects on breeding phenology and success}

We carried out exploratory analyses to identify the presence of climate impacts on breeding phenology and success, and we investigated whether there have been any interannual trends in the timing of breeding. Breeding phenology was measured as the first egg-laying date (FED). Measures of breeding success included fledgling production (number of young fledging from 
the nest), egg to fledging survival, and clutch size. Exploratory analyses were carried out using (generalised) linear mixed-effects models (G)LMMs. All exploratory analyses followed two stages: first, a base (or background) model (e.g. Öberg et al. 2015) was chosen by running a selection of candidate models incorporating potentially important variables, based on prior evidence; and second, climate indices were incorporated into the selected base model to test for their effect. The variables that were incorporated into the candidate base models for measures of breeding success included FED, proportion of territory comprising agriculture, elevation, nest cavity type, clutch size, male prior breeding experience and pair prior breeding experience, and for phenology they included elevation, female age, male age and male prior breeding experience (see Supplementary Methods and Supplementary Table 1).

Once a base model had been selected, it was run again with one of a selection of climate indices systematically included as additive effects. The climate indices tested included total rainfall, number of raindays, number of 90th percentile raindays, rainfall on 90th percentile raindays, duration of maximum rain and dry spells, mean maximum temperature, number of hot days ( $>90$ th percentile), cyclone occurrence and seasonal drought (see Supplementary Methods and Supplementary Table 2). All continuous climate indices were added as linear and quadratic terms only. Nest-level time windows for climate indices (e.g. Öberg et al. 2015) were used in the analyses of impacts on breeding success. These time windows were estimated from the FED of each breeding attempt and characterise conditions that may have affected the outcome in each case. It should be noted that nest-level climate indices for temporally overlapping nests are not truly independent, as they are derived from the same weather station data. Nevertheless, they serve to estimate the exposure of each nest to certain conditions. Climate indices of interest were defined for an 80-day period encompassing the incubation phase, brood phase and 10 days just prior to the FED for the fledgling production analysis, a 35-day period for the brood phase of each nest for the egg survival analysis, and a 10-day period just prior to the FED for the clutch size analysis (see Supplementary Methods for details). Indices were also calculated for the three-month period July-September (JAS) for the phenology analyses, as conditions in this period at the start of the breeding season have been shown to be influential on the timing of egg-laying (Nicoll 2004; Senapathi et al. 2011). August rainfall frequency has been shown to have a delaying influence on FED (Senapathi et al. 2011), but JAS indices are used here as temperature is also analysed, and conditions in July and September may influence the onset of courtship in early breeders and egg-laying by later breeders. In this study, JAS is referred to as 'late winter-early spring', based on austral seasons.

The analyses of climate effects on fledgling production, egg survival and clutch size included 403 unmanaged first clutches in the 1990/1991-2014/2015 seasons. Unmanaged clutches are those that were not manipulated for the purposes of conservation management. Second and third clutches were excluded because of the likely costs incurred during the breeding attempts that preceded re-laying. The analysis of climate effects on FED included 356 unmanaged first clutches in the 1994/1995-2014/ 2015 seasons, with at least 10 clutches per season. Overall trends in the timing of breeding were analysed using data from a larger sample of 489 unmanaged first clutches with data on FED in 20 seasons from 1994/1995 to 2014/2015, in which there were also at least 10 such clutches per season with data on FED and female identity. On this basis, there were insufficient samples of unmanaged nests to reliably study timing in earlier years. 


\subsection{Phenological plasticity}

The exploratory analysis of climate impacts on breeding phenology combines the variance in FED observed within individuals and between individuals. To disentangle these two sources of variance a method known as within-subject centering (van de Pol and Verhulst 2006; van de Pol and Wright 2009) was applied to the most parsimonious climate index from the exploratory analyses of breeding phenology. The analysis of within- and between-individual phenological responses of Mauritius kestrels to spring rainfall has been carried out in previous research (Senapathi et al. 2011). In the present study, the dataset used in the FED analyses was subset so that it contained only females with data on at least two breeding attempts. This analysis therefore utilised data from 2 to 9 years for each of 92 females, totalling 308 unmanaged first clutches. The same base model used for the exploratory phenology analyses was used again in these plasticity analyses. Additional models were constructed in which the mean of the climate index for each female across multiple years was used to describe the between-individual variance in FED; the difference between this mean value for each female and the conditions in each year was used to describe the within-individual variance in FED. To determine if the difference between the within- and between-individual variance in FED was significant, as model was constructed including the original climate index and the new term for between-individual variance. In this model, the term for between-individual variance represents the difference between the within-individual and between-individual effects (van de Pol and Wright 2009). To estimate the amount of variation in the slopes of within-individual FED responses, a model was constructed in which a random slope for the within-individual response was added to the random intercept for female identity.

\subsection{Rainy season onset}

Previous research has identified December rainfall as having a negative impact on breeding success in Mauritius kestrels (Nicoll 2004; Senapathi et al. 2011; Cartwright et al. 2014). To test this pattern further, recently developed methods (Liebmann et al. 2012; Dunning et al. 2016) were used to identify the onset and cessation of the rainy season (RS) in the Bambou Mountains. Onset and cessation were analysed using the Mt Camizard rain gauge data, and identified from accumulated daily rainfall anomalies (Liebmann et al. 2012; Dunning et al. 2016). Further details of these methods are provided in the Supplementary Methods.

The notional overlap of nesting attempts (including the incubation and brood phases) with RS onset was estimated by calculating the expected fledging day (expected hatch day + 35 days) of each clutch relative to the day of onset. The effect of overlap with onset on fledgling production was tested with mixed models, using linear, quadratic and cubic terms to test for nonlinearity, as the start of the rainy season could result in an abrupt change in breeding success. We also tested for interactions with the total amount of rainfall 50 days before and after RS onset. This was studied for 19 years in the period 1994/1995-2014/2015, with 1998/ 1999 excluded due to a missed rainy season (duration $=3$ days) and 2006/2007 excluded due to insufficient data on kestrel nests. This analysis included 433 unmanaged first clutches for which data were available on FED, clutch size, fledgling production and identity of the female, and in years with at least 10 clutches with these data available. It should be noted that some nests will have failed before the RS began; however, we do not have reliable data to indicate at what stage nests failed, so we refer to the temporal overlap of the expected fledging day with the RS as 'notional overlap'. We carried out further analyses to test for interannual trends in the 
timing of the RS, the average amount of overlap, the probability of overlap using a binomial model, and mean fledgling production, as estimated using a mixed model, and to compare mean fledging production in years with and without overlap. RS onset usually occurs later in the breeding season, thus earlier breeders might be expected to show less overlap with the RS, so we also tested whether the amount of overlap is related to the timing of breeding.

\subsection{Statistical methods}

The R statistical environment (version 3.4.4; R Core Team 2018) was used for all statistical analyses. Details of the $\mathrm{R}$ packages used are provided in the Supplementary Methods. The error distribution of response variables was assessed with the aid of histograms and Cullen and Frey graphs. FED and clutch size were assumed to follow a Gaussian error distribution. In fledgling production models, a Poisson error distribution was assumed and the log-linear link function used, and in the egg survival models a binomial error distribution was assumed and logit link function used. Egg survival was modelled as two-vector matrix of eggs that fledged and eggs that failed in each nest, following Cartwright et al. (2014). All mixed-effects models incorporated female identity and year as random effects in order to control for repeated (nonindependent) observations from the same individuals and repeated season-level conditions not included in the fixed effects. All continuous explanatory variables in the mixed-effects models were centred and scaled, and the BOBYQA (Bound Optimisation By Quadratic Approximation) optimiser (Powell 2009) was used in all GLMMs to facilitate model convergence. All simple fixed effects included in mixed models showed variance inflation factors of $<3$. Akaike's information criterion corrected for sample size (AICc) was used for comparison of mixed-effects models. The threshold of $\triangle \mathrm{AICc}=2$ was used to guide stringent model selection. Marginal and conditional pseudo- $r^{2}$ values (Nakagawa and Schielzeth 2013) were calculated for mixed models. In correlation and trend analyses, Kendall's tau and the MannKendall test were used where the assumptions of parametric tests were not sufficiently met, otherwise ordinary least squares regression was used. The results were considered significant where $p<0.05$.

\section{Results}

\subsection{Trends and plasticity in breeding phenology}

Data on the FED of 489 unmanaged first clutches show that the timing of egg-laying has significantly advanced at the rate of $\sim 0.7$ days year ${ }^{-1}$ over the period 1994-2014 $(n=20$ years, 13-30 clutches per year), based on annual mean values of FED $\left(b=-0.675 \pm 0.163, r^{2}=\right.$ $0.488, p=0.0006$, Fig. 1a) and annual median values of FED $\left(b=-0.719 \pm 0.148, r^{2}=0.569\right.$, $p=0.0001$, Fig. 1a). Trends in FED for a sample of 453 clutches for which the identity of the breeding female was recorded are nearly identical for annual means $\left(b=-0.642 \pm 0.168, r^{2}=\right.$ $0.449, p=0.0012)$ and medians $\left(b=-0.695 \pm 0.146, r^{2}=0.557, p=0.0002\right)$. These phenological shifts by breeding kestrels imply that timing is responding to an aspect of the local climate that also shows a systematic trend.

Exploratory analyses of climate impacts on phenology (Supplementary Tables 3 and 4) indicate that the timing of egg-laying is strongly influenced by July-September mean maximum temperature (JAS mean Tmax), while the frequency of raindays during the same period 

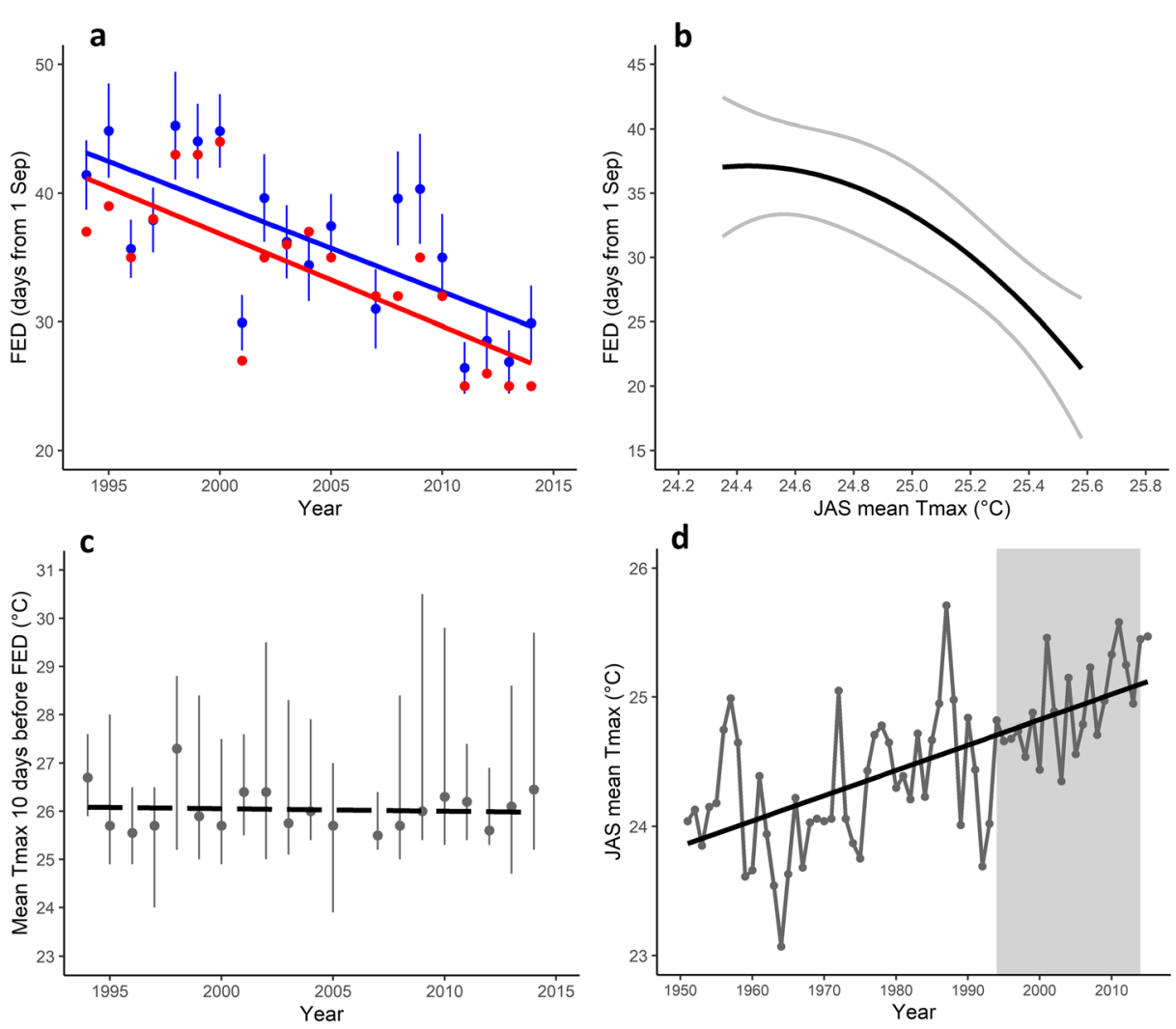

Fig. 1 Evidence that the breeding phenology of Mauritius kestrels in the Bambou Mountains is advancing and shows plasticity in response to temperature: a Trend in mean $( \pm \mathrm{SE})$ (blue) and median (red) first egg-laying dates (FED, days from 1 September) by year between 1994 and 2014; trend lines fitted using least squares regression. b Effect plot of FED (with $95 \%$ confidence intervals) in relation to July-September mean maximum temperature (JAS mean Tmax, ${ }^{\circ} \mathrm{C}$ ), extracted from a model incorporating the effects of female age ${ }^{2}$, male age ${ }^{2}$ and JAS raindays $^{2}$, with female identity and year as random effects. $\mathbf{c}$ Trend in annual median values (with minimum and maximum shown) of mean maximum temperature (Mean Tmax, ${ }^{\circ} \mathrm{C}$ ) 10 days before FED, between 1994 and 2014; dashed trend line fitted using least squares regression. d Trend in JAS mean Tmax between 1951 and 2015; trend line fitted using least squares regression; the shaded area indicates the period for which the impacts of rainy season onset on breeding success are analysed in this study

(JAS raindays) also has a relatively weak delaying influence (Supplementary Table 4; also see Senapathi et al. 2011). Of the models tested, only those incorporating JAS mean Tmax as quadratic or linear terms $(\mathrm{AICc}=2810.139$ and 2810.526$)$ or JAS raindays as quadratic or linear terms $(\mathrm{AICc}=2821.010$ and 2821.171) are more parsimonious $(\triangle \mathrm{AICc}>2)$ compared to the base model $(\mathrm{AICc}=2824.996)$. Models with quadratic terms for these indices show marginally stronger support than models with linear terms. A model incorporating quadratic terms for both JAS mean Tmax and JAS raindays shows stronger support (AICc $=2804.987$ ) than a model with JAS mean Tmax only (AICc $=2810.139$, Supplementary Table 4), although JAS mean Tmax retains a dominant influence on FED (Fig. 1b). Models that incorporate other combinations of climate indices could be more parsimonious but were not tested in this study. Mixed models incorporating year as a continuous variable, to control for potentially confounding correlations with time (see Iler et al. 2017), confirm that mean Tmax and raindays are influencing FED (Supplementary Table 5). Annual median values in mean Tmax 10 days 
before FED in the 489 clutches for which timing was analysed imply that the peak in egglaying usually occurs when the average Tmax is $25.5-26.5^{\circ} \mathrm{C}$ and show no directional trend across years $\left(b=-0.005 \pm 0.017, r^{2}=0.005, p=0.762\right.$, Fig. 1c), indicating that this has not changed during the study period despite the trend towards earlier breeding.

Further analysis to test if variance in the timing of egg-laying is due to within-individual plasticity in female kestrels shows that the population-level response to JAS mean Tmax arises from both within-individual and between-individual responses (Table 1). Both the term for within-individual variance and the term for between-individual variance are statistically significant. The coefficient estimates suggest that, while the between-individual response is about twice that of the within-individual response, the within-individual variance accounts for about double the influence on the population-level response to JAS mean Tmax compared to the between-individual variance. These results confirm the presence of phenological plasticity in response to temperature changes. The variance between females in their within-individual responses is quite low (standard deviation $=0.33$ days $0.1^{\circ} \mathrm{C}^{-1}$ ), indicating that there is limited variation between individuals in their response to temperature changes.

These analyses provide strong evidence that kestrels are tracking warming in late winterearly spring, while also responding to rainfall to a lesser extent. Mean maximum temperature in JAS shows an increase between 1951 and 2015 (Mann-Kendall tau =0.482, 2-tailed $p<0.001, n=65$, Fig. 1d), with a warming rate of $0.020{ }^{\circ} \mathrm{C}$ year ${ }^{-1}$ estimated by least squares regression. The warming trend is also evident over the period 1994-2014 (Mann-Kendall tau $=0.455$, 2-tailed $p=0.003, n=21$ ) for which kestrel phenology is studied here, with an increase of $0.035^{\circ} \mathrm{C}$ year $^{-1}$. JAS raindays show an increase between 1962 and 2015 (MannKendall tau $=0.436$, 2-tailed $p<0.001$ ); however, there is no trend evident between 1994 and 2014 (Mann-Kendall tau $=-0.044$, 2-tailed $p=0.808$ ).

\subsection{Rainfall impacts on breeding success}

The exploratory analysis of nest-level climate influences on breeding success indicates that rainfall indices are the most parsimonious and that increasing rainfall exposure throughout the

Table 1 Model comparison and parameter estimates in the analysis of plasticity in first egg-laying dates of Mauritius kestrels in response to July-September mean maximum temperature (Mean Tmax)

\begin{tabular}{|c|c|c|c|c|c|}
\hline Model & $\ln (\mathrm{L})$ & $\mathrm{AICc}$ & Fixed effect & $\begin{array}{l}\text { Coefficient estimate } \\
( \pm \mathrm{SE})\end{array}$ & $p$ value \\
\hline \multirow[t]{2}{*}{ Base + Tmax + Difference } & \multirow[t]{2}{*}{-1182.013} & \multirow[t]{2}{*}{2384.767} & Mean Tmax & $-0.90 \pm 0.29$ & 0.005 \\
\hline & & & $\begin{array}{l}\text { Within-Betw. } \\
\text { Difference }\end{array}$ & $-0.94 \pm 0.45$ & 0.041 \\
\hline \multirow[t]{2}{*}{ Base + Within + Between } & \multirow[t]{2}{*}{-1182.299} & \multirow[t]{2}{*}{2385.338} & Within-ind. & $-0.90 \pm 0.29$ & 0.005 \\
\hline & & & Between-ind. & $-1.84 \pm 0.37$ & $<0.001$ \\
\hline \multirow{2}{*}{$\begin{array}{l}\text { Base + Within + Between + } \\
\quad(\text { Within|Fem })\end{array}$} & \multirow[t]{2}{*}{-1181.724} & \multirow[t]{2}{*}{2388.505} & Within-ind. & $-0.90 \pm 0.28$ & 0.004 \\
\hline & & & Between-ind. & $-1.85 \pm 0.37$ & $<0.001$ \\
\hline Base + Tmax & -1185.016 & 2388.636 & Mean Tmax & $-1.25 \pm 0.26$ & $<0.001$ \\
\hline
\end{tabular}

The models test the significance of within-individual responses (Within-ind.), between-individual responses (Between-ind.) and the difference between the within- and between-individual responses (Within-Betw. Difference). Coefficient estimates have been converted to days $0.1{ }^{\circ} \mathrm{C}^{-1}$. The base model includes female age and male age as continuous fixed effects, both with quadratic terms. All models include female identity and year as random effects, except where the random effects also have within-individual responses nested in female identity (Within|Fem). $\ln (L)$, log-likelihood 
active phase of nesting attempts and during the brood phase of nests has a negative impact on the production of fledglings and survival of eggs to fledging (Supplementary Fig. 1, Supplementary Tables 6-9). In the fledgling production analyses, only the model including a linear term for total rainfall ( $\mathrm{AICc}=1237.840)$ is more parsimonious $(\triangle \mathrm{AICc}>2)$ compared to the base model ( $\mathrm{AICc}=1240.650)$. In the egg survival analyses, only models incorporating linear terms for total rainfall $(\mathrm{AICc}=1145.495)$ and the number of raindays exceeding the 90th percentile $(\mathrm{AICc}=1146.345)$ are more parsimonious than the base model $(\mathrm{AICc}=1148.417)$. Models incorporating total rainfall, rather than indices for extreme raindays only ( $>$ seasonal 90th percentile), are slightly better supported, suggesting that all raindays or days exceeding a threshold below the 90th percentile are contributing to the negative impact. However, extreme raindays appear to account for a large proportion of the rainfall impact. There is no evidence to support climate impacts on clutch size (Supplementary Tables 10 and 11). Likewise, there is no evidence that JAS mean Tmax alters the seasonal decline in clutch size, as a model including only $\mathrm{FED}^{2}(\mathrm{AICc}=775.313)$ is not improved by JAS mean Tmax as an additive effect $(\mathrm{AICc}=781.237)$ or by an interaction between $\mathrm{FED}^{2}$ and $\mathrm{JAS}$ mean $\mathrm{Tmax}(\mathrm{AICc}=$ 795.268).

Results from the analysis of RS onset and cessation are summarised in the Supplementary Results. Over the period 1994/1995-2014/2015, the duration of the RS varied from 52 to 209 days (excluding 1998/1999 due to a missed rainy season). The notional overlap of nesting attempts with RS onset ranged from -122 days to 76 days. Analyses show that notional overlap of nesting with RS onset has a negative impact on fledgling production and that this relationship is nonlinear (Table 2, Fig. 2a). The extent of the negative impact of overlap with onset is mediated by the amount of rainfall during the first 50 days of the RS and the amount of rainfall 50 days before onset (Table 2, Fig. 2b). There is no evidence that the seasonal decline in clutch size (Supplementary Fig. 2) confounds the pattern of lower fledgling production in later nests that overlap with the RS (Supplementary Results). Breeding kestrels therefore incur reproductive fitness costs when nesting activity coincides with RS onset.

The data on overlap show that later breeding increases overlap with the onset of the RS (Kendall's tau $=0.323, p<0.0001, n=433$, Fig. 2c), indicating one of the mechanisms through which earlier breeding pairs tend to show higher breeding success (Fig. 2d; also see Senapathi et al. 2011). Mean annual fledgling production, as estimated using a mixed model with female identity as a random effect, was compared in years showing no overlap $(n=5)$

Table 2 Effect of notional overlap with rainy season onset (overlap, days) and rainfall (RF, mm) 50 days before and after onset on fledgling production in Mauritius kestrel breeding attempts

\begin{tabular}{|c|c|c|c|c|c|c|c|}
\hline Model & $\mathrm{df}$ & $\ln (\mathrm{L})$ & $\mathrm{AICc}$ & $\triangle \mathrm{AICc}$ & $\begin{array}{l}\text { AIC } \\
\text { weight }\end{array}$ & $\begin{array}{l}\text { Marginal } \\
\text { pseudo- } r^{2}\end{array}$ & $\begin{array}{l}\text { Conditional } \\
\text { pseudo- } r^{2}\end{array}$ \\
\hline $\begin{array}{l}\text { Overlap }{ }^{3} \times \text { RF } 50 \mathrm{~d} \text { after } \\
\text { onset }\end{array}$ & 10 & -655.377 & 1331.276 & 0.000 & 0.987 & 0.318 & 0.354 \\
\hline $\begin{array}{l}\text { Overlap }{ }^{3} \times \text { RF } 50 \text { d before } \\
\text { onset }\end{array}$ & 10 & -659.813 & 1340.148 & 8.872 & 0.012 & 0.376 & 0.425 \\
\hline Overlap $^{3}$ & 6 & -666.096 & 1344.389 & 13.113 & 0.001 & 0.173 & 0.243 \\
\hline Overlap ${ }^{2}$ & 5 & -668.628 & 1347.396 & 16.120 & 0.000 & 0.119 & 0.202 \\
\hline Overlap & 4 & -674.832 & 1357.758 & 26.482 & 0.000 & 0.041 & 0.137 \\
\hline Null & 3 & -682.883 & 1371.822 & 40.546 & 0.000 & 0.000 & 0.116 \\
\hline
\end{tabular}

All models include female identity and year as random effects. Where quadratic and cubic terms are included, only the highest order term is shown for brevity. $d f$, degrees of freedom; $\ln (L)$, log-likelihood 

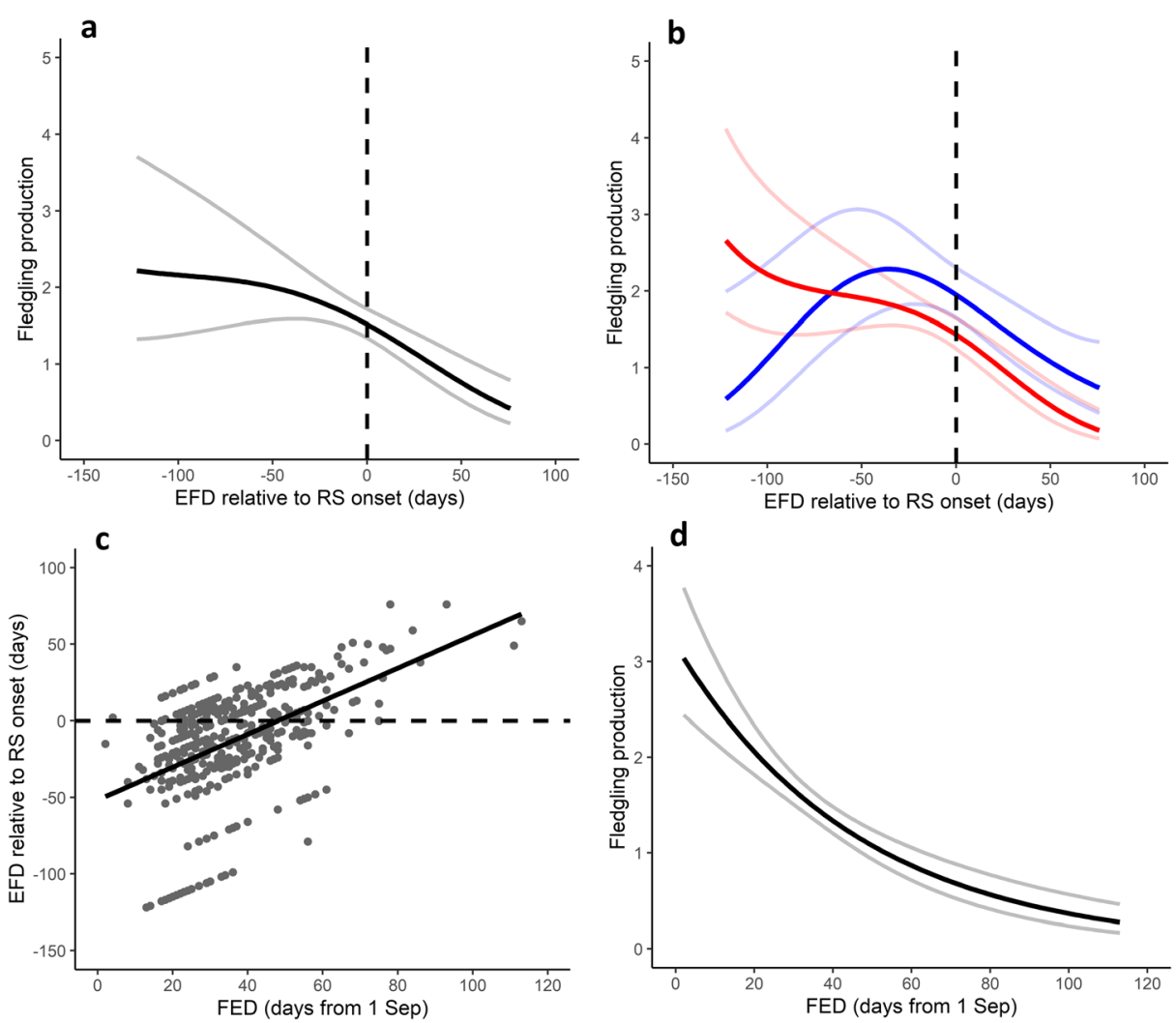

Fig. 2 Evidence from Mauritius kestrel nests in the Bambou Mountains that temporal overlap with the rainy season reduces breeding success and that this favours earlier breeding: a Effect plot of fledgling production (with 95\% confidence intervals) in relation to expected fledging day (EFD) relative to rainy season (RS) onset (indicating notional overlap with onset in days), extracted from a model incorporating female identity and year as random effects. b Effect plot of fledgling production (with 95\% confidence intervals) in relation to EFD relative to RS onset (indicating notional overlap with onset in days) when there is $500 \mathrm{~mm}$ of rain 50 days after onset (blue line) and $1000 \mathrm{~mm}$ of rain 50 days after onset (red line), extracted from a model incorporating female identity and year as random effects. $\mathbf{c}$ EFD relative to RS onset (indicating notional overlap with onset in days) in relation to first egg-laying date (FED, days from 1 September); trend line fitted using least squares regression. d Effect plot of fledgling production (with 95\% confidence intervals) in relation to FED, extracted from a model incorporating female identity and year as random effects

with years in which at least some nesting attempts overlapped with the RS ( $n=15)$. Years in which the sample of nests does not overlap with the RS tend to show higher mean fledgling production (median of years: 1.620, range: 1.389-2.186) than years with some overlap (median of years: 1.421 , range: 1.176-1.807), although the difference is marginally nonsignificant (Wilcoxon-Mann-Whitney test, $U=60, p=0.053$ ).

\subsection{Breeding phenology in relation to rainy season onset}

If RS onset lacks a directional trend, advances in breeding phenology might be expected to reduce the risk of overlap with onset and so be accompanied by a negative interannual trend in notional overlap and a resultant positive trend in annual mean fledging production; however, there is no evidence of these patterns in the data. Annual mean fledgling production, as 
estimated using a mixed model, shows only a weak non-significant decrease (Mann-Kendall tau $=-0.253,2$-tailed $p=0.127, n=20$ years, Fig. 3a). This appears to result from a lack of an interannual trend in overlap with RS onset. There is no trend across years in the amount of notional overlap, based on annual mean expected fledging days (EFD) (Mann-Kendall tau $=-$ $0.006, p=1.000, n=19$ years, Fig. 3b) and median EFD (Mann-Kendall tau $=-0.029, p=$ $0.861, n=19$ years, Fig. 3b), with slopes of -0.207 and -0.266 respectively, as estimated with least squares regression. A binomial regression model indicates that there is no trend across years in the probability of overlap with the RS by at least 1 day $(b=-0.008 \pm 0.016$, $z=-0.494, p=0.621, n=433$ clutches, Fig. $3 c$ ). These results imply that the onset of the RS is also advancing to some extent. There is indeed an apparent trend of advancing RS onset, at a rate of -0.431 days year ${ }^{-1}$ over the period 1966-2014 (Fig. 3d), and -0.363 days year ${ }^{-1}$ over the period 1994-2014, based on least squares regression; a rate that is comparable to the rate at which the timing of egg-laying is advancing. This pattern appears to be influenced by
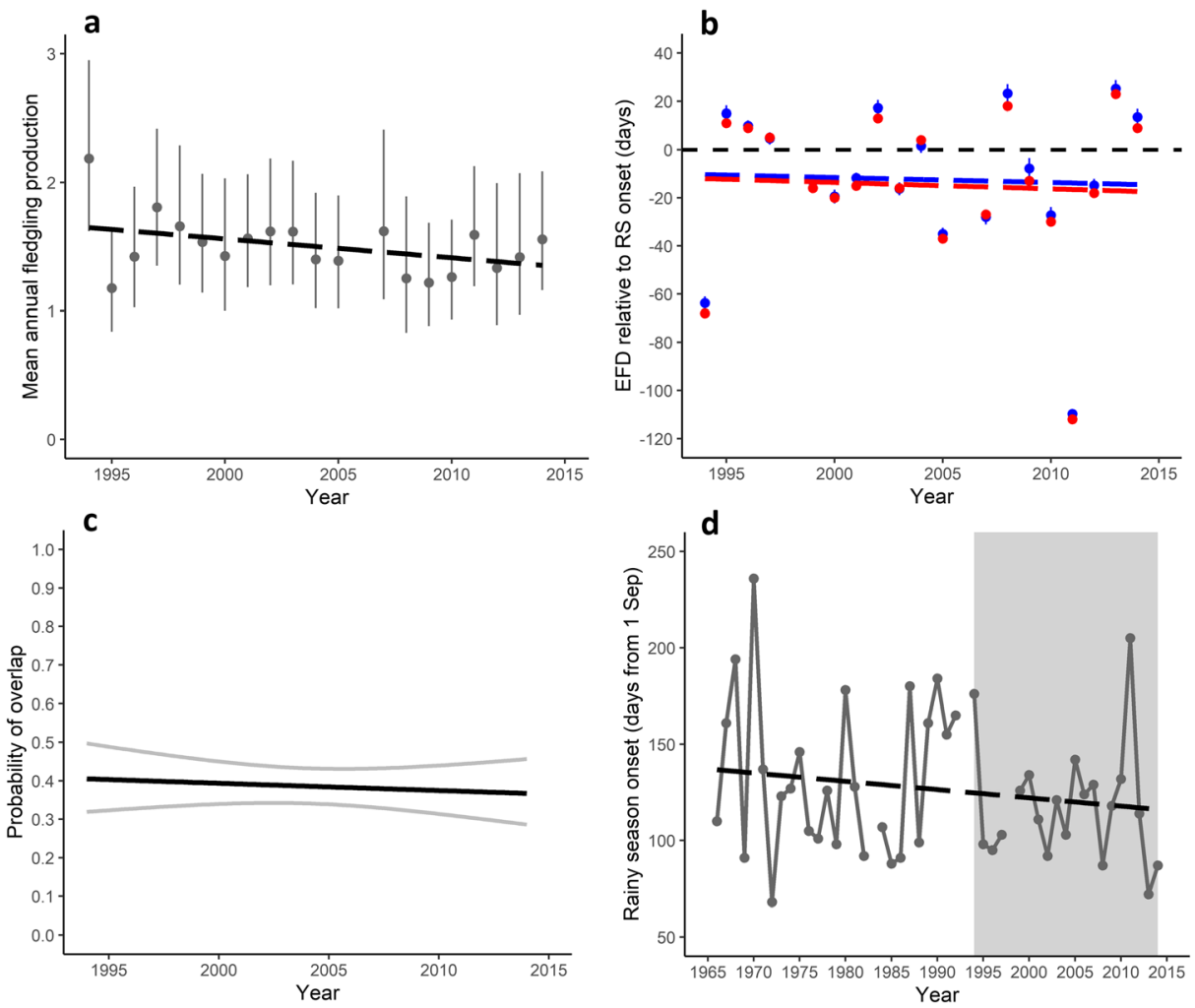

Fig. 3 Evidence that advancement in the timing of breeding by Mauritius kestrels in the Bambou Mountains during the period 1994-2014 has tracked a seasonal window of favourable conditions: a Interannual trend in annual mean fledgling production, as extracted from a mixed model with female identity as a random effect; dashed trend line fitted using least squares regression; error bars show $95 \%$ confidence intervals. b Trend in annual mean $( \pm \mathrm{SE})$ (blue data points and line) and median (red data points and line) expected fledging day (EFD) relative to rainy season (RS) onset (indicating notional overlap with onset in days); dashed trend lines fitted using least squares regression. c Effect plot of probability of overlap with the RS by at least 1 day (with $95 \%$ confidence intervals) in relation to year. d Trend in the timing of RS onset between 1966 and 2014; dashed trend line fitted using least squares regression; the shaded area indicates the period for which the impacts of RS onset on breeding success are analysed in this study; missing data points indicate absent RSs (see Supplementary Results) 
increasingly earlier onset in some later years. However, nonparametric trend results do not approach statistical significance for the period 1966-2014 (Mann-Kendall tau $=-0.103,2$ tailed $p=0.320, n=46$ years) or 1994-2014 (Mann-Kendall tau $=-0.064$, 2-tailed $p=0.721$, $n=20$ years). This is because the timing of RS onset shows high interannual variability and is stochastic in its local occurrence. Across the 19 years studied here, the mean ( $\pm 1 \mathrm{SD}$ ) of annual mean overlap is $-12.5 \pm 32.6$ days, showing that on average kestrel breeding is timed for fledging to occur just before RS onset. Overall, these analyses suggest that the trend in kestrel breeding phenology has tracked the occurrence of earlier onset in some later years, such that population-level breeding success is not negatively impacted.

\section{Discussion}

The results of our analyses, taken together, demonstrate three important observations: (1) that a tropical bird species shows phenological advances driven by plasticity primarily in response to warming temperatures, as has already been documented for many temperate species; (2) that this tropical bird species synchronises its breeding season with a seasonal climate window, defined by late winter-early spring temperatures and the onset of the RS, and tracks changes in this window in an adaptive manner; and, (3) that phenotypic plasticity contributes to the adaptive capacity of a small insular population recovering from a severe population bottleneck. The response of kestrels to temperature, and to a lesser extent rainfall frequency, in late winterearly spring is probably adaptive because the phenological reactions to these aspects of the climate are likely to be sufficient to track long-term changes in the timing of RS onset. These cues, however, are not sufficient to track high interannual variability in the local timing of onset. Nevertheless, kestrels are able to track changes in the seasonal climate window with negligible fitness consequences. These observations are made possible by the detailed, individual-based data collected on Mauritius kestrels.

Evidence from phenological data from a range of species supports the general expectation that endotherms are less sensitive to abiotic conditions (Cohen et al. 2018), and this may be assumed to be particularly true at tropical latitudes, where temperature variability is relatively limited (Pearce-Higgins and Green 2014). However, the present study provides compelling evidence of high sensitivity to increasing temperatures in a tropical endotherm occupying a high trophic level. The rates of advancement across years shown by Mauritius kestrels are similar to those reported for some temperate bird populations (e.g. Both et al. 2004) and for animals globally (Cohen et al. 2018), although the responses in Mauritius kestrels are to relatively limited temperature changes. It is not possible in this study to ascertain whether breeding kestrels are using temperature as a direct cue or tracking earlier prey availability as temperatures increase. Cole and Harris (2011) characterized the months of May-August as the cold wet season on Ile aux Aigrettes, an offshore islet located c.5 km from the Bambou Mountains, and found that diurnal activity in day geckos (Phelsuma ornata) was lower in these months compared to other times of year. Increases in temperature may therefore influence the activity patterns of geckos and thus prey availability for kestrels. Burgess et al. (2011) suspected that the timing of the kestrel breeding season may be influenced by gecko (Phelsuma spp.) densities. The monitoring of gecko density and activity patterns could provide further insights.

The results of the breeding success analyses show that early breeders tend to be more successful, in part because they avoid overlap with the onset of the RS, and hence reduce the 
adverse impacts of associated heavy rainfall events on fledgling production. Heavy rainfall is likely to reduce hunting efficiency, hunting opportunities and prey availability, thus limiting the ability of adults to obtain enough food for their chicks (Carter 1991; Senapathi et al. 2011). Heavy rain may also lead to hypothermia in chicks if nests are flooded (Senapathi et al. 2011). Therefore, in most years there is selection for early breeding in order to avoid an overlap of the brood phase with the onset of the rains and potentially with heavy rainfall. The advantage of earlier breeding is amplified in years with heavy rainfall in the first weeks after the onset of the rains. The local timing of RS onset is evidently highly stochastic and represents a highly variable risk to breeding kestrels. A limitation of this analysis is that there are no data to investigate whether there are peaks in prey abundance that could also influence fitness and selection on timing.

Given past episodes of climate change and variability in Mauritius during the Quaternary Period (Rijsdijk et al. 2011; Van Der Plas et al. 2012), it is to be expected that the Mauritius kestrel has evolved or retained adaptive plasticity in response to climate. However, our results imply that phenological responses have been retained by the population that are sufficient for the tracking of recent changes in the local climate, despite the genetic legacy of nearextinction. Previous research has shown that there is very little heritable genetic variation for mean egg-laying date in this species (Senapathi 2009), and the low variation in responses between individual females shown in the present study indicates that there is also limited standing genetic variation for plasticity. This could be a result of the population bottleneck or a small ancestral population (Senapathi 2009), or due to purifying selection under predictable environmental variability (e.g. Oostra et al. 2018). Analysis of neutral genetic variation in the Mauritius kestrel indicates that the genetic diversity of the ancestral population was high and comparable to that of mainland kestrel species (Groombridge et al. 2000). It is unclear whether further changes in the local climate will require responses beyond those shown by the population, but the response observed so far may 'buy time' while future management actions are developed (e.g. Nicotra et al. 2015).

Our analyses might be limited by the use of weather data from only one rain gauge and one synoptic station. However, the locations of these stations should ensure that they provide reliable indications of conditions experienced by Mauritius kestrels in the Bambou Mountains. In addition, there are some limitations to the rainy season analysis methods used in this study. For the identification of onset and cessation, the methods require runs of consistent above-average precipitation, producing a pronounced increase in the cumulative daily anomaly, and as a consequence intermittent or light rainfall at the beginning or end of the season would not be considered part of the RS (Dunning et al. 2016). In general, this methodology is particularly suited to regions that experience fairly consistent, well-defined and pronounced annual rainfall seasonality (Liebmann et al. 2012). However, in the Bambou Mountains in eastern Mauritius the contrasts between rainy and dry seasons can be less pronounced.

The projected emergence of some tropical regions from recent climate variability and occurrence of novel climates this century (Williams et al. 2007; Mora et al. 2013; Hawkins et al. 2014; Mahony and Cannon 2018) raises the prospect of other strong phenological changes in tropical species. Furthermore, climate research has indicated large-scale trends in the seasonality of rainfall in the tropics, with some regions seeing an increasing contrast between rainy and dry seasons, while other regions experience a reduction in this seasonality (Feng et al. 2013). Precipitation patterns in the tropics are projected to change substantially during this century, although there is inconsistency among models (Kent et al. 2015; 
Chadwick et al. 2016). Such changes are likely to affect phenology and alter the impacts of seasonal precipitation transitions on fitness and population dynamics.

Seasonal climate windows and their dynamics may be widespread phenomena through which tropical species respond to climate change. They may be particularly relevant to regions that have pronounced contrasts between rainy and dry seasons, and their prevalence may increase towards the subtropics as annual temperature cycles become more pronounced. The defining characteristics of seasonal windows will depend on the ecology and underlying seasonality of each species and the local annual climate cycle. Future changes in temperature and precipitation in the tropics, relative to past variability, may be such that they result in the creation of new seasonal climate windows to which tropical species must synchronise their life-history events. A better understanding of such complex dynamics in local climate, and their effects on phenology, individual fitness and demography, as well as better understanding of the potential for adaptive plasticity in island species, will be essential for safeguarding many species in a changing climate.

Supplementary Information The online version contains supplementary material available at https://doi.org/ 10.1007/s10584-021-02971-y.

Acknowledgements The monitoring and management of the Mauritius kestrel population in the Bambou Mountains is part of a long-term species recovery programme conducted by the Mauritian Wildlife Foundation, with support from the Institute of Zoology (ZSL), University of Reading, University of Kent, Durrell Wildlife Conservation Trust, the Peregrine Fund, the National Parks and Conservation Service (Government of Mauritius), Vallee de Ferney Trust and local corporate sponsors. We gratefully acknowledge the landowners and many fieldworkers involved in monitoring the population. We are grateful to Ferney Sugar Estate for contributing rain gauge data to this study. We also thank Mauritius Meteorological Services for making weather station data publicly available. J. Pearce-Higgins and T. Oliver provided helpful comments on an earlier version of the analysis. We are grateful to K. Keogan and two anonymous reviewers for their comments, which greatly improved the manuscript.

Authors' contributions The study was conceptualised by KN, MACN, EB and PLV. The ecological analyses were designed and carried out by JT, with input from KN, MACN, EB and PLV. The rainy season onset and cessation analysis was designed by CMW and EB and carried out by CMW. Ecological data were contributed by VT and CGJ. The initial manuscript was drafted by JT and reviewed by all authors. Funding was acquired by $\mathrm{KN}$.

Funding This study was funded through a doctoral studentship from the UK Natural Environment Research Council (NERC), as part of the NERC SCENARIO Doctoral Training Partnership, under grant NE/L002566/1.

Data availability The ecological data used in the present study are available on reasonable request from the Institute of Zoology, Zoological Society of London. The meteorological data used are available publicly and from Ferney Sugar Estate on request.

\section{Compliance with ethical standards}

Conflict of interest The authors declare that they have no conflict of interest.

Ethics approval Field work that contributed to this study adhered to the ethics policies of the Mauritian Wildlife Foundation. 
Consent to participate Not applicable.

Consent for publication All authors have approved the manuscript for publication.

Code availability The software and R packages used are cited in the manuscript and supplementary material. Bespoke code is available on request from the corresponding author (JT).

Open Access This article is licensed under a Creative Commons Attribution 4.0 International License, which permits use, sharing, adaptation, distribution and reproduction in any medium or format, as long as you give appropriate credit to the original author(s) and the source, provide a link to the Creative Commons licence, and indicate if changes were made. The images or other third party material in this article are included in the article's Creative Commons licence, unless indicated otherwise in a credit line to the material. If material is not included in the article's Creative Commons licence and your intended use is not permitted by statutory regulation or exceeds the permitted use, you will need to obtain permission directly from the copyright holder. To view a copy of this licence, visit http://creativecommons.org/licenses/by/4.0/.

\section{References}

Beever EA, O’Leary J, Mengelt C et al (2016) Improving conservation outcomes with a new paradigm for understanding species' fundamental and realized adaptive capacity. Conserv Lett 9:131-137. https://doi.org/ 10.1111/conl.12190

Berglund H, Järemo J, Bengtsson G (2009) Endemism predicts intrinsic vulnerability to nonindigenous species on islands. Am Nat 174:94-101. https://doi.org/10.1086/598501

Both C, Artemyev AV, Blaauw B et al (2004) Large-scale geographical variation confirms that climate change causes birds to lay earlier. Proc R Soc Lond B Biol Sci 271:1657-1662. https://doi.org/10.1098/rspb.2004. 2770

Burgess MD, Nicoll MAC, Jones CG, Norris K (2011) Multiple environmental gradients affect spatial variation in the productivity of a tropical bird population. J Anim Ecol 80:688-695. https://doi.org/10.1111/j.13652656.2011.01816.x

Carter JE (1991) Home range, habitat utilization, and prey delivery patterns of the Mauritius kestrel (Falco punctatus). MSc Thesis, Boise State University

Cartwright SJ, Nicoll MAC, Jones CG, Tatayah V, Norris K (2014) Agriculture modifies the seasonal decline of breeding success in a tropical wild bird population. J Appl Ecol 51:1387-1395. https://doi.org/10.1111/ 1365-2664.12310

Chadwick R, Good P, Martin G, Rowell DP (2016) Large rainfall changes consistently projected over substantial areas of tropical land. Nat Clim Chang 6:177-181. https://doi.org/10.1038/nclimate2805

Charmantier A, Gienapp P (2014) Climate change and timing of avian breeding and migration: evolutionary versus plastic changes. Evol Appl 7:15-28. https://doi.org/10.1111/eva.12126

Cohen JM, Lajeunesse MJ, Rohr JR (2018) A global synthesis of animal phenological responses to climate change. Nat Clim Chang 8:224-228. https://doi.org/10.1038/s41558-018-0067-3

Cole NC, Harris S (2011) Environmentally-induced shifts in behavior intensify indirect competition by an invasive gecko in Mauritius. Biol Invasions 13:2063-2075. https://doi.org/10.1007/s10530-011-0025-8

Dawson TP, Jackson ST, House JL, Prentice IC, Mace GM (2011) Beyond predictions: biodiversity conservation in a changing climate. Science 332:53-58. https://doi.org/10.1126/science.1200303

Donelson JM, Salinas S, Munday PL, Shama LNS (2018) Transgenerational plasticity and climate change experiments: where do we go from here? Glob Chang Biol 21:2954-2962. https://doi.org/10.1111/gcb. 13903

Dunning CM, Black ECL, Allan RP (2016) The onset and cessation of seasonal rainfall over Africa. J Geophys Res Atmos 121:11405-11424. https://doi.org/10.1002/2016JD025428

Ewing SR, Nager RG, Nicoll MAC, Aumjaud A, Jones CG, Keller LF (2008) Inbreeding and loss of genetic variation in a reintroduced population of Mauritius kestrel. Conserv Biol 22:395-404. https://doi.org/10. 1111/j.1523-1739.2008.00884.x

Feng X, Porporato A, Rodriguez-Iturbe I (2013) Changes in rainfall seasonality in the tropics. Nat Clim Chang 3 : 811-815. https://doi.org/10.1038/nclimate1907 
Foden WB, Butchart SHM, Stuart SN et al (2013) Identifying the world's most climate change vulnerable species: a systematic trait-based assessment of all birds, amphibians and corals. PLoS One 8:e65427. https:// doi.org/10.1371/journal.pone.0065427

Forrest J, Miller-Rushing AJ (2010) Toward a synthetic understanding of the role of phenology in ecology and evolution. Philos Trans R Soc Lond Ser B 365:3101-3112. https://doi.org/10.1098/rstb.2010.0145

Gordo O, Doi H (2012) Spring phenology delays in an insular subtropical songbird: is response to climate change constrained by population size? J Ornithol 153:355-366. https://doi.org/10.1007/s10336-011-0750-x

Groombridge JJ, Jones CG, Bruford MW, Nichols RA (2000) 'Ghost' alleles of the Mauritius kestrel. Nature 403:616. https://doi.org/10.1038/35001148

Hawkins E, Anderson B, Diffenbaugh N et al (2014) Uncertainties in the timing of unprecedented climates. Nature 511:E3-E5. https://doi.org/10.1038/nature13523

Hidalgo Aranzamendi N, Hall ML, Kingma SA, van de Pol M, Peters A (2019) Rapid plastic breeding response to rain matches peak prey abundance in a tropical savanna bird. J Anim Ecol 88:1799-1811. https://doi.org/ $10.1111 / 1365-2656.13068$

Iler AM, Inouye DW, Schmidt NM, Høye TT (2017) Detrending phenological time series improves climatephenology analyses and reveals evidence of plasticity. Ecology 98:647-655. https://doi.org/10.1002/ecy.1690

Jones CG (1987) The larger land-birds of Mauritius. In: Diamond AW (ed) Studies of Mascarene island birds. Cambridge University Press, Cambridge, pp 208-300

Jones CG, Heck W, Lewis RE, Mungroo Y, Slade G, Cade T (1995) The restoration of the Mauritius kestrel Falco punctatus population. Ibis 137:S173-S180. https://doi.org/10.1111/j.1474-919X.1995.tb08439.x

Kent C, Chadwick R, Rowell DP (2015) Understanding uncertainties in future projections of seasonal tropical precipitation. J Clim 28:4390-4413. https://doi.org/10.1175/JCLI-D-14-00613.1

Kier G, Kreft H, Lee TM, Jetz W, Ibisch PL, Nowicki C, Mutke J, Barthlott W (2009) A global assessment of endemism and species richness across island and mainland regions. Proc Natl Acad Sci U S A 106:93229327. https://doi.org/10.1073/pnas.0810306106

Knapp KR, Kruk MC, Levinson DH, Diamond HJ, Neumann CJ (2010) The international best track archive for climate stewardship (IBTrACS): unifying tropical cyclone data. Bull Am Meteorol Soc 91:363-376. https:// doi.org/10.1175/2009BAMS2755.1

Komdeur J (1996) Seasonal timing of reproduction in a tropical bird, the Seychelles warbler: a field experiment using translocation. J Biol Rhythm 11:333-346. https://doi.org/10.1177/074873049601100407

Komdeur J, Daan S (2005) Breeding in the monsoon: semi-annual reproduction in the Seychelles warbler (Acrocephalus sechellensis). J Ornithol 146:305-313. https://doi.org/10.1007/s10336-005-0008-6

Liebmann B, Bladé I, Kiladis GN, Carvalho LMV, Senay GB, Allured D, Leroux S, Funk C (2012) Seasonality of African precipitation from 1996 to 2009. J Clim 25:4304 4322. https://doi.org/10.1175/JCLI-D-11-00157.1

Lind MI, Johansson F (2007) The degree of adaptive phenotypic plasticity is correlated with the spatial environmental heterogeneity experienced by island populations of Rana temporaria. J Evol Biol 20: 1288-1297. https://doi.org/10.1111/j.1420-9101.2007.01353.x

Mahony CR, Cannon AJ (2018) Wetter summers can intensify departures from natural variability in a warming climate. Nat Commun 9:783. https://doi.org/10.1038/s41467-018-03132-z

Miller-Rushing AJ, Høye TT, Inouye DW, Post E (2010) The effects of phenological mismatches on demography. Philos Trans R Soc Lond Ser B 365:3177-3186. https://doi.org/10.1098/rstb.2010.0148

Mora C, Frazier AG, Longman RJ et al (2013) The projected timing of climate departure from recent variability. Nature 502:183-187. https://doi.org/10.1038/nature12540

Nakagawa S, Schielzeth H (2013) A general and simple method for obtaining $R^{2}$ from generalized linear mixedeffects models. Methods Ecol Evol 4:133-142. https://doi.org/10.1111/j.2041-210x.2012.00261.x

Nevoux M, Arlt D, Nicoll M, Jones C, Norris K (2013) The short- and long-term fitness consequences of natal dispersal in a wild bird population. Ecol Lett 16:438-445. https://doi.org/10.1111/ele.12060

Nicoll MAC (2004) The ecology and management of a re-introduced population of the Mauritius Kestrel (Falco punctatus). $\mathrm{PhD}$ Thesis, University of Reading

Nicotra AB, Beever EA, Robertson AL, Hofmann GE, O’Leary J (2015) Assessing the components of adaptive capacity to improve conservation and management efforts under global change. Conserv Biol 29:12681278. https://doi.org/10.1111/cobi.12522

Nussey DH, Wilson AJ, Brommer JE (2007) The evolutionary ecology of individual phenotypic plasticity in wild populations. J Evol Biol 20:831-844. https://doi.org/10.1111/j.1420-9101.2007.01300.x

Öberg M, Arlt D, Pärt T, Laugen AT, Eggers S, Low M (2015) Rainfall during parental care reduces reproductive and survival components of fitness in a passerine bird. Ecol Evol 5:345-356. https://doi.org/10.1002/ece3.1345

Oostra V, Saastamoinen M, Zwaan BJ, Wheat CW (2018) Strong phenotypic plasticity limits potential for evolutionary responses to climate change. Nat Commun 9:1005. https://doi.org/10.1038/s41467-018-03384-9

Parmesan C, Root TL, Willig MR (2000) Impacts of extreme weather and climate on terrestrial biota. Bull Am Meteorol Soc 81:443-450. https://doi.org/10.1175/1520-0477(2000)081<0443:IOEWAC >2.3.CO;2 
Pearce-Higgins JW, Green RE (2014) Birds and climate change: impacts and conservation responses. Cambridge University Press, Cambridge

Pearce-Higgins JW, Lindley PJ, Johnstone IG, Thorpe RI, Douglas DJT, Grant MC (2019) Site-based adaptation reduces the negative effects of weather upon a southern range margin Welsh black grouse Tetrao tetrix population that is vulnerable to climate change. Clim Chang 153:253-265. https://doi.org/10.1007/s10584019-02372-2

Porlier M, Charmantier A, Bourgault P, Perret P, Blondel J, Garant D (2012) Variation in phenotypic plasticity and selection patterns in blue tit breeding time: between- and within-population comparisons. J Anim Ecol 81:1041-1051. https://doi.org/10.1111/j.1365-2656.2012.01996.x

Post E, Steinman BA, Mann ME (2018) Acceleration of phenological advance and warming with latitude over the past century. Sci Rep 8:3927. https://doi.org/10.1038/s41598-018-22258-0

Powell MJD (2009) The BOBYQA algorithm for bound constrained optimization without derivatives. Centre for Mathematical Sciences, University of Cambridge, Cambridge

R Core Team (2018) R: a language and environment for statistical computing. R Foundation for Statistical Computing, Vienna. www.R-project.org

Rijsdijk KF, Zinke J, de Louw PGB et al (2011) Mid-Holocene (4200 kyr BP) mass mortalities in Mauritius (Mascarenes): insular vertebrates resilient to climatic extremes but vulnerable to human impact. Holocene 21:1179-1194. https://doi.org/10.1177/0959683611405236

Rodrigues ASL, Brooks TM, Butchart SHM, Chanson J, Cox N, Hoffmann M, Stuart SN (2014) Spatially explicit trends in the global conservation status of vertebrates. PLoS One 9:e113934. https://doi.org/10.1371/ journal.pone.0113934

Senapathi GD (2009) Assessing the effect of changing climatic conditions in Mauritius on the population dynamics of the endemic Mauritius kestrel (Falco punctatus). PhD Thesis, University of Reading

Senapathi D, Underwood F, Black E, Nicoll MAC, Norris K (2010) Evidence for long-term regional changes in precipitation on the East Coast Mountains in Mauritius. Int J Climatol 30:1164-1177. https://doi.org/10. 1002/joc. 1953

Senapathi D, Nicoll MAC, Teplitsky C, Jones CG, Norris K (2011) Climate change and the risks associated with delayed breeding in a tropical wild bird population. Proc R Soc Lond B Biol Sci 278:3184-3190. https://oi. org/10.1098/rspb.2011.0212

Staub CG, Stevens FR, Waylen PR (2014) The geography of rainfall in Mauritius: modelling the relationship between annual and monthly rainfall and landscape characteristics on a small volcanic island. Appl Geogr 54:222-234. https://doi.org/10.1016/j.apgeog.2014.08.008

Temple SA (1987) Foraging ecology of the Mauritius kestrel (Falco punctatus). Biotropica 19:2-6. https://doi. org/10.2307/2388453

van de Pol M, Verhulst S (2006) Age-dependent traits: a new statistical model to separate within- and betweenindividual effects. Am Nat 167:766-773. https://doi.org/10.1086/503331

van de Pol M, Wright J (2009) A simple method for distinguishing within- versus between-subject effects using mixed models. Anim Behav 77:753-758. https://doi.org/10.1016/j.anbehav.2008.11.006

Van Der Plas GW, De Boer EJ, Hooghiemstra H, Florens FBV, Baider C, Van Der Plicht J (2012) Mauritius since the last glacial: environmental and climatic reconstruction of the last 38000 years from Kanaka crater. J Quat Sci 27:159-168. https://doi.org/10.1002/jqs.1526

Visser ME (2008) Keeping up with a warming world; assessing the rate of adaptation to climate change. Proc R Soc Lond B Biol Sci 275:649-659. https://doi.org/10.1098/rspb.2007.0997

Visser ME, Both C (2005) Shifts in phenology due to global climate change: the need for a yardstick. Proc R Soc Lond B Biol Sci 272:2561-2569. https://doi.org/10.1098/rspb.2005.3356

Wikelski M, Thom C (2000) Marine iguanas shrink to survive El Niño. Nature 403:37-38. https://doi.org/10. $1038 / 47396$

Wikelski M, Hau M, Robinson WD, Wingfield JC (2003) Reproductive seasonality of seven Neotropical passerine species. Condor 105:683-695. https://doi.org/10.1093/condor/105.4.683

Williams JW, Jackson ST, Kutzbach JE (2007) Projected distributions of novel and disappearing climates by 2100 AD. Proc Natl Acad Sci U S A 104:5738-5742. https://doi.org/10.1073/pnas.0606292104

Williams SE, Shoo LP, Isaac JL, Hoffman AA, Langham G (2008) Towards an integrated framework for assessing the vulnerability of species to climate change. PLoS Biol 6:2621-2626. https://doi.org/10.1371/ journal.pbio.0060325

Publisher's note Springer Nature remains neutral with regard to jurisdictional claims in published maps and institutional affiliations. 


\section{Affiliations}

Joseph Taylor ${ }^{1,2,3} \cdot$ Malcolm A. C. Nicoll ${ }^{2}$ - Emily Black ${ }^{4,5}$. Caroline M. Wainwright ${ }^{4,5}$. Carl G. Jones ${ }^{6,7} \cdot$ Vikash Tatayah $^{7} \cdot$ Pier Luigi Vidale ${ }^{4,5} \cdot$ Ken Norris ${ }^{2,8}$

1 Centre for Agri-Environmental Research, School of Agriculture, Policy and Development, University of Reading, Reading RG6 6AR, UK

2 Institute of Zoology, Zoological Society of London, London NW1 4RY, UK

3 Present address: Natural Environment Research Council, Polaris House, North Star Avenue, Swindon SN2 $1 \mathrm{EU}, \mathrm{UK}$

4 Department of Meteorology, University of Reading, Reading RG6 6BB, UK

5 National Centre for Atmospheric Science, Reading, UK

6 Durrell Wildlife Conservation Trust, Les Augrès Manor, Trinity, Jersey JE3 5BP, UK

7 Mauritian Wildlife Foundation, Grannum Road, Vacoas, Mauritius

8 Present address: Natural History Museum, Cromwell Road, London SW7 5BD, UK 